\title{
Establishment of a canine model of human type 2 diabetes mellitus by overexpressing phosphoenolypyruvate carboxykinase
}

\author{
YEON WOO JEONG ${ }^{1}$, GEUN-SHIK LEE ${ }^{2}$, JOUNG JOO KIM ${ }^{1}$, SUN WOO PARK ${ }^{1}$, KYEONG HEE KO ${ }^{1}$, \\ MINA KANG ${ }^{1}$, YU KYUNG KIM ${ }^{1}$, EUI-MAN JUNG ${ }^{3}$, SANG HWAN HYUN ${ }^{4}$, \\ TAEYOUNG SHIN $^{1}$, EUI-BAE JEUNG ${ }^{3}$ and WOO SUK HWANG ${ }^{1}$
}

${ }^{1}$ SooAm Biotech Research Foundation, Seoul 152-904; ${ }^{2}$ Laboratory of Veterinary Physiology, College of Veterinary Medicine, Kangwon National University, Chucheon 200-701; ${ }^{3}$ Laboratory of Veterinary Biochemistry and Molecular Biology and

${ }^{4}$ Laboratory of Veterinary Embryology and Biotechnology, College of Veterinary Medicine, Chungbuk

National University, Cheongju 361-763, Republic of Korea

Received February 15, 2012; Accepted April 10, 2012

DOI: $10.3892 / \mathrm{ijmm} .2012 .993$

\begin{abstract}
Dogs are useful models for studying human metabolic diseases such as type 2 diabetes mellitus due to similarities in physiology, anatomy and life styles with humans. Somatic cell nuclear transfer (SCNT) facilitates the production of transgenic dogs. In this study, we generated transgenic dogs expressing the phosphoenolpyruvate carboxykinase (PEPCK) gene, which is closely involved in the pathogenesis of type 2 diabetes mellitus. In addition, we assessed the cloning efficiency associated with adult or fetal (cloned or natural mating) fibroblasts as a nuclear source. Cloning efficiency was determined by the fusion, pregnancy and cloning rates. The fusion rates were significantly high for fibroblasts from cloned fetuses, but the pregnancy and cloning rates were relatively high for cells from normal fetuses. Based on these data, fetal fibroblasts were selected as the nuclear donor for SCNT and genetically engineered to overexpress the $P E P C K$ gene and dual selection marker genes controlled by the PEPCK promoter. The transgenic cells were introduced into oocytes and transferred into five recipient dogs, resulting in two pregnancies. Finally, three puppies were born and confirmed by microsatellite analysis to be genetically identical to the donor. One puppy successfully overexpressed PEPCK
\end{abstract}

Correspondence to: Professor Woo-Suk Hwang, SooAm Biotech Research Foundation, San 43-41 Oryu-dong, Guro-gu, Seoul 152-904, Republic of Korea

E-mail: hwangws@sooam.org

Professor Eui-Bae Jeung, Laboratory of Veterinary Biochemistry and Molecular Biology, College of Veterinary Medicine, Chungbuk National University, Chungbuk, Cheongju 361-763, Republic of Korea E-mail: ebjeung@cbu.ac.kr

Key words: type 2 diabetes mellitus, canine disease model, phosphoenolpyruvate carboxykinase, somatic cell nuclear transfer, transgenic $\operatorname{dog} \mathrm{s}$
mRNA and protein in the liver. This canine disease model may be useful for studying the pathogenesis and/or therapeutic targets of type 2 diabetes mellitus.

\section{Introduction}

Since the development of somatic cell nuclear transfer (SCNT) and the production of a cloned sheep in 1997 (1), a number of scientists have successfully manipulated somatic cells from several species to produce cloned offspring using similar methods (2-9). Although the characteristics of canine reproductive physiology and early development have not been extensively studied, the techniques used to clone canines has evolved dramatically since the first dog was cloned (5). A number of recent studies reported successful generation of cloned small-breed (10), medium-sized (11) and large-breed dogs (12). Furthermore, another group described the production of one dog cloned from somatic cells that had been cryopreserved for a long period of time using in vivo oocyte collection protocols (13).

The techniques for generating transgenic mice are well characterized comparing to those used to produce other species, and these mice have been widely used as models of human diseases (14). Gene manipulation of germ line cells and treatment with specific drugs often cause diseases that closely resemble human disorders with respect to phenotype and underlying pathological mechanisms (15-17). However, mouse models cannot fully reflect human disease processes. Thus, alternative animals are needed to come over this limitation. One of the best animals is the dog, which serves as a valuable model of human diseases and can be used to validate experimental approaches which are enhanced by a specific understanding of the genome of different dog breeds (18). In addition, dogs have habitation characteristics similar to those of humans, comparable organ sizes and typically receive exceptional medical care compared to small laboratory animals (19). With these advantages, combining techniques for dog cloning and genetic manipulation will pave the way for gene function studies involving the disruption or introduction 
Table I. Primer sequences.

\begin{tabular}{lccl}
\hline Name & Restriction enzyme & Direction & \multicolumn{1}{c}{ Sequences $\left(5^{\prime} \rightarrow 3^{\prime}\right)$} \\
\hline Dog $P E P C K$ promoter $(-3,180)$ & NheI & $\mathrm{F}$ & GCTAGCCATGGCTTCCTTTCCACT \\
Dog $P E P C K$ promoter $(-2,349)$ & NheI & $\mathrm{F}$ & GCTAGCGACAGTTGCAAAGGAATAA \\
Dog $P E P C K$ promoter $(-1,018)$ & NheI & $\mathrm{F}$ & GCTAGCAAGGGCATTGAGAAGTGT \\
Dog $P E P C K$ promoter $(-746)$ & NheI & $\mathrm{F}$ & GCTAGCTCCTATAGGCCTTGGCTG \\
Dog $P E P C K$ promoter $(+1)$ & $N c o \mathrm{I}$ & $\mathrm{R}$ & CCATGGCCAAGGCTTCCTGAAACA \\
$P E P C K$ cDNA & NcoI & $\mathrm{F}$ & CCATGGCGAGGTCATCCCAAAACAAG \\
$P E P C K$ cDNA & $X b a \mathrm{I}$ & $\mathrm{R}$ & TCTAGAGGGTCTGATCACATCTGGCT \\
EGFP cDNA & $E c o$ RV & $\mathrm{F}$ & GATATCCACAACCATGGTGAGCAAGGGCGA \\
EGFP cDNA & BamHI & $\mathrm{R}$ & GGATCCTTACTTGTACAGCTCGTCCATGCC \\
Confirmation primer $a$ & & $\mathrm{~F}$ & CATGAAGCAGCACGACTTCT \\
Confirmation primer $b$ & & $\mathrm{R}$ & CCTAGGAATGCTCGTCAAGA \\
Confirmation primer $c$ & & $\mathrm{~F}$ & TCCTATAGGCCTTGGCTG \\
Confirmation primer $d$ & & $\mathrm{R}$ & GGGTCTGATCACATCTGGCT \\
$P E P C K$ & & $\mathrm{~F}$ & GACATCGCCTGGATGAAGTT \\
$P E P C K$ & & $\mathrm{R}$ & CCAGTGCCTGGTCAATACCT \\
$G A P D H$ & & $\mathrm{~F}$ & AGAACATCATCCCTGCTTC \\
$G A P D H$ & & $\mathrm{R}$ & TTGAAGTCACAGGAGACCAC \\
\hline
\end{tabular}

of specific genes, targeting of genes and molecular characterization of human hereditary diseases in mammalian species.

In the present study, we generated transgenic dogs overexpressing phosphoenolpyruvate carboxykinase (PEPCK), a key gluconeogenic enzyme in the liver and kidneys that has an established role in metabolic intermediates (20). Mice overexpressing PEPCK share key characteristics with those of humans with type 2 diabetes mellitus (21). Based on previously established mouse models, we first assessed the promoter activities of canine PEPCK and generated targeting vectors to produce the model of type 2 diabetes mellitus. In addition, we optimized the nuclear source of SCNT to increase the cloning efficiency of transgenic dogs. Finally, we determined that PEPCK was overexpressed in the transgenic dogs.

\section{Materials and methods}

Animal care. The female mixed breed dogs (1- and 7-year-old, $20-25 \mathrm{~kg}$ ) used for our study were housed singly. They were fed a standard commercial dog diet (Suwon Purina, Suwon, Kyunggi-Do, Korea) once a day and given water ad libitum in accordance with the animal study guidelines of the SooAm Biotech Research Foundation for Accreditation for Laboratory Animal Care.

Establishment and culturing of fibroblast cell lines. Unless otherwise indicated, all cells were grown at $37^{\circ} \mathrm{C}$. All cell culture materials were obtained from Invitrogen Life Technologies (Carlsbad, CA, USA) and the other chemicals from SigmaAldrich (St. Louis, MO, USA). Adult fibroblasts were isolated from the abdominal skin of a 2-year-old beagle dog (Medicare Animal Hospital, Suwon, Kyunggi-Do, Korea). Normal or cloned fetal fibroblasts were from fetuses recovered on gestation Day 25 after mating or embryo transfer. Fetuses of the beagles were retrieved aseptically by laparotomy. The isolated tissues were minced with a surgical blade in a culture dish (35- or 100-mm; Becton Dickinson, Lincoln Park, NJ, USA) and dissociated in DMEM supplemented with $0.1 \%$ (w/v) trypsin $/ 1 \mathrm{mM}$ EDTA for 1-2 h. Trypsinized cells were subsequently cultured for 6-8 days in DMEM supplemented with 10\% (v/v) FBS, 1 mM sodium pyruvate, $1 \%(\mathrm{v} / \mathrm{v})$ non-essential amino acids (NEAA) and a $10 \mu \mathrm{g} / \mathrm{ml}$ penicillin/streptomycin solution. When the cells were fully confluent, they were collected by trypsinization and were frozen in DMEM supplemented with $40 \%$ FBS and $10 \%$ dimethyl sulfoxide (DMSO).

Genomic DNA extraction and PCR. Genomic DNA was isolated with a G-DEX ${ }^{\mathrm{TM}}$ IIc Genomic DNA extraction kit (Intron Biotechnology, Suwon, Korea). Genomic DNA (1 $\mu \mathrm{g})$ was amplified in a $20-\mu 1$ PCR reaction containing $1 \mathrm{U}$ Ex-Taq polymerase (Takara Bio, Inc., Shiga, Japan), 2 mM dNTP (Takara Bio, Inc.) and $10 \mathrm{pmol}$ of specific primers. The details of all primers are provided in Table I. The PCR reactions were denatured at $95^{\circ} \mathrm{C}$ for $30 \mathrm{sec}$, annealed at $62^{\circ} \mathrm{C}$ for $30 \mathrm{sec}$ and extended at $72^{\circ} \mathrm{C}$ for 1 or $3 \mathrm{~min}$. The PCR products $(8 \mu \mathrm{l})$ were separated on a $0.7 \%$ agarose gel, stained with ethidium bromide and photographed using Gel Doc EQ (Bio-Rad, Hercules, CA, USA).

Promoter study. Unless otherwise indicated, all restriction enzymes were obtained from Takara Bio, Inc. The canine $P E P C K$ promoter from $-3,180$ nucleotide (nt) to $+1 \mathrm{nt}(+1$, the transcriptional start site) was isolated by PCR using genomic DNA from beagle fibroblasts as a template and included an NheI site at the $5^{\prime}$ end and a NcoI site at the $3^{\prime}$ end. Amplified fragments were digested by the restriction enzymes and ligated into the promoterless pGL3-Basic vector (Promega Corporation, Madison, WI, USA). The PEPCK promoterconjugated luciferase construct shown in Fig. 1, was transiently transfected into hepatoma cells (H4IIE; American Type Culture Collection, Manassas, VA, USA) using Lipofectamine ${ }^{\mathrm{TM}} 2000$ 
(Invitrogen Life Technologies) according to the manufacturer's instructions. To control different transfection efficiencies of the various luciferase constructs, the Rous sarcoma virus (RSV)-lacZ plasmid was co-transfected into H4IIE cells.

Briefly, $3 \times 10^{5}$ cells were seeded in 6-well tissue culture plates (BD Biosciences, Franklin Lakes, NJ, USA) one day before transfection. Four micrograms of the luciferase constructs and $0.5 \mu \mathrm{g}$ of RSV-lacZ plasmid were co-transfected into the cells. After transfection for $4 \mathrm{~h}$, media were replaced with DMEM containing $10 \% \mathrm{FBS}$ and $1 \mathrm{mM}$ dexamethasone for other $48 \mathrm{~h}$. Cellular lysates were prepared using $150 \mu \mathrm{l}$ of reporter lysis buffer (Promega Corporation) and assayed for luciferase activity using the luciferase assay system (Promega Corporation). Luminescence was measured using a GloMax ${ }^{\circledR}$ 20/20 Luminometer (Promega Corporation) and $\beta$-galactosidase activity was measured using a $\beta$-galactosidase enzyme assay system (Promega Corporation). Promoter activity was calculated as relative luciferase normalized by $\beta$-galactosidase activity (\%).

Targeting vector construction. PEPCK cDNA was prepared by PCR using cDNA from beagle liver as a template. Amplified fragments were digested with $N c o I$ and $X b a I$ and ligated into the recombinant pGL3_PEPCK promoter $(-746$ to $+1 \mathrm{nt})$ plasmid to replace the luciferase gene. The selection cassette plasmid was made in several steps. Enhanced green fluorescence protein (EGFP) was amplified by PCR using pIRES2_EGFP (BD Biosciences) as a template. The fragments were digested with EcoRV and BamHI and ligated into the pIRES_Neo vector (BD Biosciences). The selection cassette was amplified by PCR using the recombinant pIRES_EGFP plasmid containing a neomycin resistance gene $\left(\mathrm{Neo}^{\mathrm{r}}\right)$. The selection cassette fragments were digested with $M l u \mathrm{I}$ and NheI, and ligated into the recombinant pGL3_PEPCK promoter_PCPEK cDNA plasmid. The targeting vectors sequences were confirmed by nucleotide sequencing (Genotech Co., Ltd., Daejeon, Korea).

Gene targeting. The structure of the targeting vector is shown in Fig. 3A. The selection cassette construct contained the cytomegalovirus (CMV) promoter, EGFP gene and $\mathrm{Neo}^{\mathrm{r}}$. The expression cassette consisted of the $\operatorname{dog} P E P C K$ promoter region $(-746$ to $+1 \mathrm{nt})$, dog PEPCK cDNA and a simian virus (SV) 40 poly-A tail signal. The targeting vector was linearized by $M l u \mathrm{I}$ digestion and transfected into normal fetal fibroblasts by Lipofectamine 2000 (Invitrogen Life Technologies).

Establishment of transgenic fibroblasts. Normal fetal fibroblasts $\left(2 \times 10^{5}\right)$ at passage 2 were seeded in a $35-\mathrm{mm}$ culture plate (BD Biosciences) 1 day before transfection. Cells were transfected with $4 \mu \mathrm{g}$ of linearized targeting vector and then cultured in DMEM containing $10 \%$ FBS and a high dose of antibiotics (600 $\mu \mathrm{g} / \mathrm{ml}$ of G418; Sigma) for 20 days. The concentration of antibiotics was further reduced to $300 \mu \mathrm{g} / \mathrm{ml}$ for additional days until single colonies appeared. The neomycin-resistant colonies were reseeded in 24-well plates (BD Biosciences) to expand the colonies for further analysis. Following several passages, the transgenic cells screened for EGFP expression and chromosomal integration of targeting vector was further confirmed by PCR-based genotyping. The colonies were expanded and frozen (6x10 ${ }^{5}$ cells/aliquot) prior to their subsequent use for SCNT.
Canine cloning. Estrous of the female dogs was followed weekly by observing vulval bleeding to detect the onset of the heat period. During heat, a blood sample $(2 \mathrm{ml})$ was collected daily at the same time by cephalic venipuncture and serum progesterone levels were assayed using a Cobas E411 (Roche Diagnostics, Indianapolis, IN, USA). Oocyte retrieval and cloned embryo transfer were performed using general surgical procedures as described in our previous study (13). Briefly, the oviducts were flushed upward with TCM-199 (Invitrogen Life Technologies) from oocyte donor dogs under surgical procedures. The oocytes were denuded and washed for nuclear transfer. The cells were then stained with $5 \mu \mathrm{g} / \mathrm{ml}$ bisbenzimide and mounted. Oocytes with a nucleus and extruded first polar body (metaphase II) were counted and used for a routine nuclear transfer procedure.

After retrieval, metaphase II oocytes were stripped from cumulus cells and enucleated by squeezing out the first polar body and the metaphase II plate into a small amount of surrounding cytoplasm using a glass pipette. The cells were transferred to the perivitelline space of the enulceated oocytes. Using a fine pipette, a trypsinized fetal fibroblast with a smooth cell surface was transferred to the perivitelline space of an enucleated oocyte. The couplets were equilibrated in a $0.26 \mathrm{M}$ mannitol solution containing $0.5 \mathrm{mM}$ of HEPES, $0.1 \mathrm{mM}$ of $\mathrm{CaCl}_{2}$ (Sigma) and $\mathrm{MgSO}_{4}$ (Sigma) for 4 min and then transferred to a chamber containing two electrodes overlaid with a mannitol solution (Sigma). The couplets were fused with two direct current pulses of 1.9-2.2 kV/cm for $30 \mu \mathrm{sec}$ using a BTX Electro-Cell Manipulator 2001 (BTX, Inc., San Diego, CA, USA). Only the fused embryos were selected and cultured for $2 \mathrm{~h}$ in modified synthetic oviductal fluid (mSOF). The formula of the mSOF was basically the same as the original formulation (11) except of the concentration of glucose $(1.5 \mathrm{mM})$ and the addition of $2 \%$ essential MEM, $1 \%$ nonessential amino acids, $8 \mathrm{mg} / \mathrm{ml}$ of BSA and $1 \%(\mathrm{v} / \mathrm{v})$ insulin, transferrin and selenium (Invitrogen Life Technologies).

Embryo transfer. Embryo recipients were anaesthetized as previously described for oocyte retrieval and placed in a ventral recumbent position. The ovary with a greater number of corpus lutuem was approached for ventral laparotomy. The fat layer covering the ovary was gently grasped with forceps and suspended with a suture to exteriorize the fimbriated end of the oviduct. The embryos were loaded into a tomcat catheter (Sovereign, Sherwood, MO, USA) and gently transferred to the 2/3 distal position of the oviduct without insufflating air. Surrogates were checked for pregnancy by transabdominal ultrasound 25-30 days after embryo transfer.

Microsatellite analysis. Parentage analysis was performed for the puppies derived from SCNT to confirm the identity of the donor cell used for nuclear transfer. Genomic DNA was extracted from each newborn puppy, recipients and donor cells. DNA microsatellite markers (PEZ1, PEZ3, PEZ5, PEZ6, PEZ8, PEZ12, PEZ20, FHC 2010, FHC 2054 and FHC 2079) were used to confirm the genetic identity of the cloned puppies, the fetuses and fibroblasts used as donor cells.

Quantitative real-time PCR. Total-RNA was extracted from the liver biopsy tissues of the cloned and transgenic 

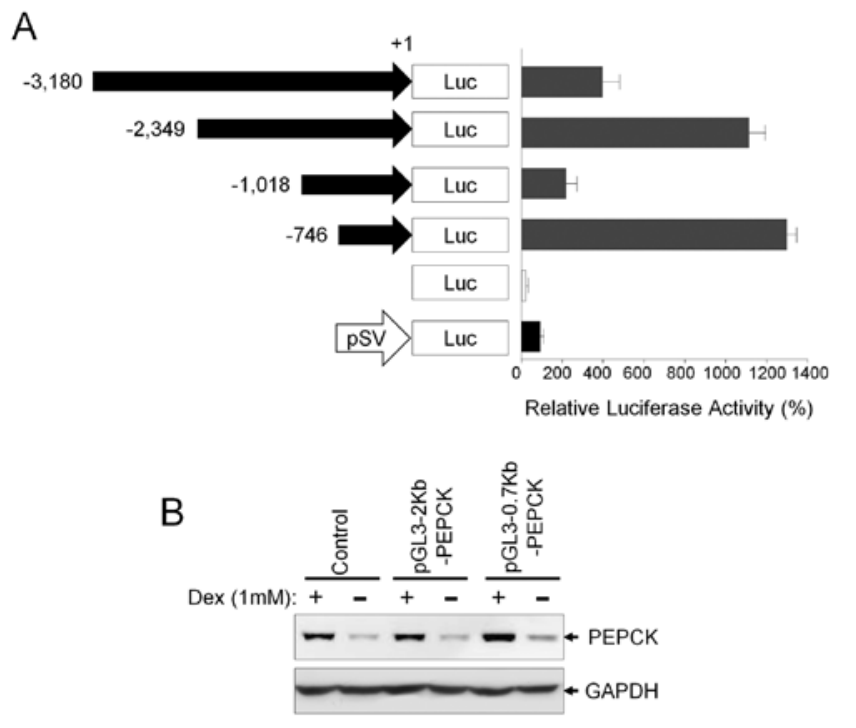

C

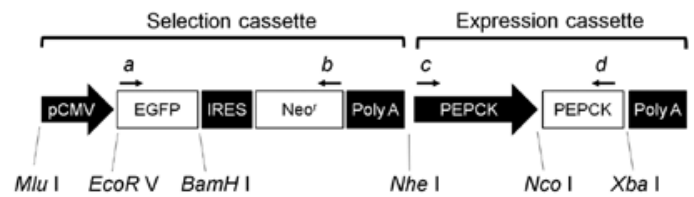

Figure 1. Canine PEPCK promoter activity in H4IIE cells. (A) A set of deletion constructs containing the indicated regions of the canine PEPCK promoter was transiently transfected into hepatoma cells (H4IIE) in the presence of dexamethasone (Dex, $1 \mathrm{mM}$ ). An RSV-lacZ expression vector was co-transfected to normalize transfection efficiency. Relative luciferase activity (RLU) is represented as the percent induction after normalization to $\beta$-galactosidase activity compared to the RLU of the simian virus 40 promoter (pSV), which was set at $100 \%$. Data represent the mean \pm SEM of 3 independent experiments each performed in triplicate. (B) H4IIE cells were transiently transfected with the empty pGL3 plasmid (control), canine PEPCK cDNA controlled by the PEPCK promoter region from -2349 to $+1 \mathrm{nt}$ (pGL3-2Kb-PEPCK), or canine PEPCK cDNA controlled by the PEPCK promoter region from -746 to $+1 \mathrm{nt}$ (pGL3-0.7Kb-PEPCK). The cells were treated with Dex $(1 \mathrm{mM},+)$ or vehicle (DMSO, -) and the cell lysates were then subjected to an immunoblot assay. (C) Schematic representation of the targeting vector divided into 2 parts (expression and selection). The expression cassettes contained dog PEPCK cDNA controlled by the PEPCK promoter $(-746$ to $+1 \mathrm{nt})$. Selection cassettes consisted of enhanced green fluorescent protein (EGFP) cDNA and neomycin resistance gene $\left(\mathrm{Neo}^{\mathrm{r}}\right)$. pCMV, cytomegalovirus promoter; IRES, internal ribosome entry site; poly A, poly A tail signal sequences. $a$ to $d$ indicates the locations and direction of primers used for genotyping.

dogs using TRIzol reagent (Invitrogen Life Technologies) according to the protocol provided by the manufacturer and the concentration of total-RNA was determined by measuring the absorbance at $260 \mathrm{~nm}$. First strand complementary DNA (cDNA) was prepared by subjecting total-RNA $(1 \mu \mathrm{g})$ to reverse transcription using M-MLV reverse transcriptase (Invitrogen Life Technologies) and random primers (9-mers; Takara Bio, Inc.). Quantitative real-time PCR was performed with $1 \mu \mathrm{l}$ of cDNA template added to $10 \mu \mathrm{l}$ of $2 \mathrm{X}$ SYBR Premix Ex Taq (Takara Bio, Inc.) containing 10 pmol each of the specific primers. Reactions were carried out for 40 cycles. The cycling parameters were as follows: denaturation at $95^{\circ} \mathrm{C}$ for $15 \mathrm{sec}$, annealing at $60^{\circ} \mathrm{C}$ for $15 \mathrm{sec}$ and extension at $72^{\circ} \mathrm{C}$ for $15 \mathrm{sec}$. Fluorescence intensity was measured at the end of the extension phase of each cycle. The threshold value of the fluorescence intensity for all the samples was set manually. The reaction cycle at which the PCR products exceeded this fluorescence intensity threshold in the exponential phase of amplification was designated as the threshold cycle (Ct).

Expression of the target gene was quantified relative to the level of an internal control gene $(G A P D H)$ based on the comparison of $\mathrm{Cts}$ at a constant fluorescence intensity. The amount of transcript present was inversely related to the observed Ct. For every two-fold dilution in the amount of transcript, the $\mathrm{Ct}$ was expected to increase by 1 . Relative expression (R) was calculated using the equation $\mathrm{R}=2^{-[\Delta \mathrm{CT} \text { sample- } \Delta \mathrm{CT} \text { control] }}$. To determine a normalized arbitrary value for each gene, every data point was normalized to the GAPDH control gene as well as to their respective controls.

Western blot analysis. Liver biopsy tissues were harvested, washed twice with ice-cold PBS and resuspended in $20 \mathrm{mM}$ Tris- $\mathrm{HCl}$ buffer $(\mathrm{pH}$ 7.4) containing protease inhibitors $(0.1 \mathrm{mM}$ phenylmethylsulfonyl fluoride, $5 \mu \mathrm{g} / \mathrm{ml}$ aprotinin, $5 \mu \mathrm{g} / \mathrm{ml}$ pepstatin $\mathrm{A}$ and $1 \mu \mathrm{g} / \mathrm{ml}$ chymostatin) and phosphatase inhibitors ( $5 \mathrm{mM} \mathrm{Na}_{3} \mathrm{VO}_{4}$ and $5 \mathrm{mM} \mathrm{NaF}$ ). All inhibitors were obtained from Sigma. Whole cell lysates were prepared with 20 strokes of a Dounce homogenizer followed by centrifugation at $13,000 \mathrm{xg}$ for $20 \mathrm{~min}$ at $4^{\circ} \mathrm{C}$. Protein concentrations were determined using a BCA assay (Sigma). The proteins (50 $\mu \mathrm{g})$ were separated with $12 \%$ SDS-PAGE and then transferred onto a polyvinylidene difluoride (PVDF) membrane (Bio-Rad). The membranes were probed with antibodies against PEPCK (diluted 1:1,000; Cayman Chemical, Ann Arbor, MI, USA) or $\beta$-actin (1:4,000; Santa Cruz Biotechnology, Inc., Santa Cruz, CA, USA). Horseradish peroxidase-conjugated anti-rabbit IgG (diluted 1:2,000; Santa Cruz Biotechnology, Inc.) were used to detect primary antibody binding and was visualized by exposure to X-ray film (Bio-Rad). The band intensities were quantified with the Gel Doc EQ system (Bio-Rad).

Statistical analysis. Data analysis was conducted using SPSS for Windows (version 15; SPSS Inc., Chicago, IL, USA) and a graph was prepared with GraphPad Prism (version 4.0) software (GraphPad Software, Inc., San Diego, CA, USA). Data for the pregnancy rate were compared using an ANOVA and the results from western blot analysis were compared using a $\mathrm{t}$-test with post hoc analysis. P-values $<0.05$ were considered to be significant.

\section{Results}

Canine PEPCK promoter activity and targeting vector construction. To determine the promoter region of the canine PEPCK gene which has the maximum activity for tissuespecific expression, we generated a series of promoter variants containing different deletions of the upstream human insulin promoter region $(-3,180$ to $+1 \mathrm{nt})$ using beagle genomic DNA. The fragments were linked to the luciferase ( $L u c$ ) gene in a promoterless pGL3-Basic vector. These PEPCK promoter constructs were finally introduced into the H4IIE hepatoma cell line and the relative promoter activities were measured in the presence of dexamethasone (Dex). As shown in Fig. 1A, pGL3-2Kb $(-2,349$ to $+1 \mathrm{nt})$ and pGL3-0.7Kb $(-746$ to $+1 \mathrm{nt})$ induced 110- and 130-fold increases in luciferase activity, 
Table II. Effects on the cloning efficiency of adult or fetal fibroblasts as the nuclear source for SCNT.

\begin{tabular}{|c|c|c|c|c|c|c|}
\hline \multirow[b]{2}{*}{ Nuclear sources } & \multicolumn{2}{|r|}{ Oocytes } & \multirow[b]{2}{*}{$\begin{array}{c}\text { Recipients } \\
\mathrm{n}\end{array}$} & \multicolumn{2}{|c|}{ Pregnant recipients, $\mathrm{n}\left(\%^{\mathrm{b}}\right)$} & \multirow[b]{2}{*}{$\begin{array}{l}\text { Delivered puppies, } \mathrm{n} \\
\text { (cloning efficiency }^{\mathrm{c}} \text { ) }\end{array}$} \\
\hline & $\begin{array}{c}\text { Total } \\
\mathrm{n}\end{array}$ & $\begin{array}{c}\text { Fused embryos } \\
\mathrm{n}\left(\%^{\mathrm{a}}\right)\end{array}$ & & $\begin{array}{l}\text { Mid-term } \\
\text { (Day 30) }\end{array}$ & Full-term & \\
\hline Adult fibroblasts & 134 & $103(76.9)$ & 6 & $1(16.6)$ & $1(16.6)$ & $1(1.0)$ \\
\hline Cloned fetal fibroblasts & 118 & $115(97.5)^{\mathrm{d}}$ & 10 & $2(20.0)$ & $1(10.0)^{\mathrm{e}}$ & $1(0.9)$ \\
\hline Fetal fibroblasts & 66 & $51(77.3)$ & 4 & $2(50.0)$ & $2(50.0)$ & $3(5.9)$ \\
\hline
\end{tabular}

${ }^{\mathrm{a}}$ No. of fused embryos/total no. of oocytes; ${ }^{\mathrm{b}}$ no. of pregnant recipients/no. of recipients; ${ }^{\mathrm{c}}$ no. of offspring/no. of fused embryos; ${ }^{\mathrm{d}} \mathrm{P}<0.05 \mathrm{vs}$. adult and cloned fetal fibroblasts; ${ }^{\mathrm{A}}$ Abortion on Day 44 of gestation.
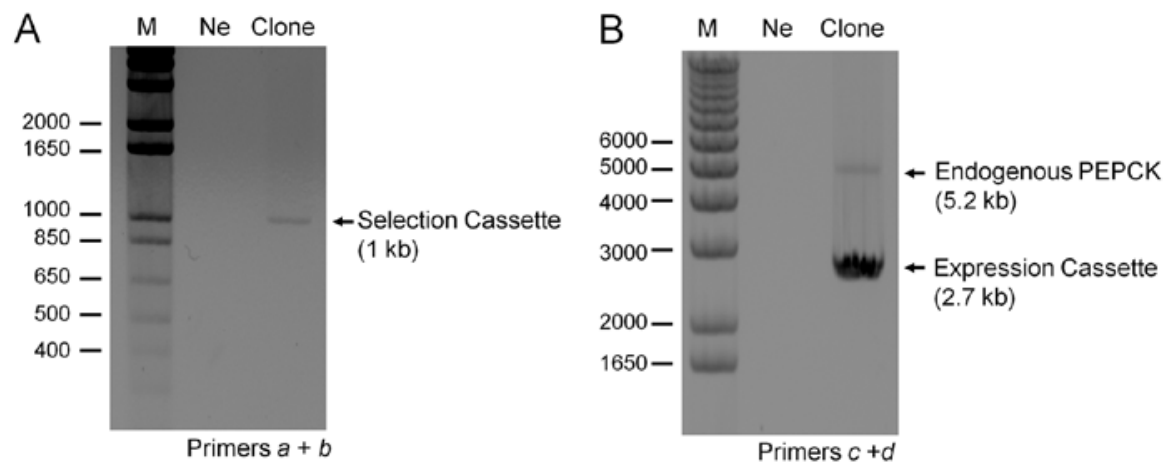

Figure 2. Identification of transgenic fibroblasts. Genomic DNA was isolated from G418 resisted transgenic fibroblasts (clone) and subjected to PCR-based genotyping. (A) Chromosomal integration of the selection cassette and (B) expression cassette was confirmed. The location and direction of primers $a$ to $d$ are presented in Fig. 1C. M, molecular weights; Ne, PCR reaction without genomic DNA.

respectively. However, a more modest increase in luciferase activity was observed with pGL3-3Kb $(-3,180$ to $+1 \mathrm{nt})$ and pGL3-1Kb $(-1,018$ to $+1 \mathrm{nt})$. Thus, we identified the two promoter regions, pGL3-2Kb and pGL3-0.7Kb, associated with the greatest luciferase activity.

We further investigated whether these selected promoters contributed to PEPCK transcription and translation. PEPCK cDNA was replaced with $L u c$ genes in pGL3-2Kb and pGL3-0.7Kb to generate pGL3-2Kb-PEPCK and pGL3$0.7 \mathrm{~Kb}$-PEPCK. These constructs were introduced into H4IIE cells. The protein levels of PEPCK were higher for pGL30.7Kb-PEPCK than pGL3-2Kb-PEPCK (Fig. 1B). Thus, pGL3-0.7Kb-PEPCK was selected as the expression cassette for the targeting vector containing dual selection marker genes, EGFP and $\mathrm{Neo}^{\mathrm{r}}$ (Fig. 1C).

In vivo development of cloned embryos from different nuclear sources of SCNT. To compare the in vivo developmental competence among different SCNT nuclear sources, fibroblasts from adult dogs, normal fetuses, or cloned fetuses were introduced into oocytes as donor cells for nuclear transfer and sequentially implanted into recipients. The fusion, pregnancy, and delivery rates were further measured (Table II). For the adult fibroblasts, 134 oocytes were used for nuclear transfer and 103 (76.9\%) reconstructed embryos were transferred to 6 recipients. For the cloned fetal fibroblasts, 118 oocytes were used for nuclear transfer and $115(97.5 \%)$ reconstructed embryos were transferred to 10 recipients. For the fetal fibroblast, 66 oocytes were used for nuclear transfer and $51(77.3 \%)$ reconstructed embryos were transferred to 4 recipients. The highest fusion rates before embryo transfer were observed for the cloned fetal fibroblast group $(\mathrm{P}<0.05)$ comparing to the other cells. For the adult fibroblasts, one pregnancy was identified at mid-term gestation (16.6\%) and reached full-term (one offspring). For the cloned fetal fibroblasts, two pregnancies were identified at mid-term (20.0\%), one pregnancy reached full-term and the other was aborted on Day 45. For the fetal fibroblasts, two recipients were confirmed pregnant and reached full-term (one singleton and one set of twins). Pregnancy rates on Day 30 were not significantly different among the cell sources. However, fetal fibroblasts as a source for nuclear transfer resulted in the best cloning efficiency $(5.9 \%)$ comparing to adult $(1.0 \%)$ or cloned fetal fibroblasts $(0.9 \%)$.

Establishment of transgenic fetal fibroblasts expressing $P E P C K$. Normal fetal fibroblasts, nuclear donor cells, were introduced by the targeting vector. After screening with antibiotics, the identity of positive clones was confirmed with PCR-based genotyping. The primers $a$ and $b$ were used to demonstrate integration of the selection cassette (Fig. 2A). Chromosomal insertion of the expression cassette was confirmed by the primers $c$ and $d$ (Fig. 2B). Endogenous PEPCK gene generated a $5.2-\mathrm{kb}$ band containing intron regions whereas the inserted expression cassette produced a 2.7-kb band. The cells found to express EGFP and possessing resistance against neomycin, were subjected to nuclear transfer. 
Table III. Summary of embryo transfers.

\begin{tabular}{lccccccc}
\hline $\begin{array}{l}\text { Surrogate } \\
\text { ID (n=5) }\end{array}$ & $\begin{array}{c}\text { Egg donor } \\
\text { ID (n=7) }\end{array}$ & $\begin{array}{c}\text { Oocytes } \\
\text { retrieved }^{\mathrm{a}}, \mathrm{n}\end{array}$ & Oocyte stage $^{\mathrm{b}}$ & $\begin{array}{c}\text { Oocytes } \\
\text { for NT (n=65) }\end{array}$ & $\begin{array}{c}\text { Fused } \\
\text { embryos }^{\mathrm{c}}, \mathrm{n}\end{array}$ & $\begin{array}{c}\text { Donor cell } \\
\text { passage }\end{array}$ & $\begin{array}{c}\text { Clinical } \\
\text { pregnancy }^{\mathrm{d}}\end{array}$ \\
\hline S1 & D1 & 13 & $\mathrm{M}$ & 10 & 7 & 6 & - \\
S2 & D2 & 12 & $\mathrm{M}$ & 12 & 9 & 6 & + \\
S3 & D3 & 12 & $\mathrm{~A}$ & 10 & 7 & 6 & + \\
S4 & D4 & 11 & $\mathrm{I}$ & 6 & 4 & 6 & - \\
& D5 & 10 & M & 10 & 7 & 6 & - \\
S5 & D6 & 9 & M & 9 & 5 & 10 & \\
& D7 & 8 & M & 8 & 8 & 10 & \\
\hline
\end{tabular}

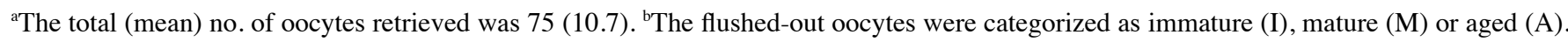
'The no. of fused embryos (\%) was 47 (72.3). ${ }^{\mathrm{d}}$ Clinical pregnancy was determined by ultrasound examination of the fetal sac in the uterus 4 weeks after embryo transfer. NT, nuclear transfer.

Table IV. Characteristics of cloned and transgenic puppies.

\begin{tabular}{lccccccc}
\hline Surrogate ID & $\begin{array}{c}\text { Embryos } \\
\mathrm{n}\end{array}$ & Offspring ID & $\begin{array}{c}\text { Gestation } \\
\text { length }^{\mathrm{a}}\end{array}$ & $\begin{array}{c}\text { Body weight } \\
\text { at birth (g) }\end{array}$ & Delivery method & $\begin{array}{c}\text { EGFP } \\
\text { expression }\end{array}$ & $\begin{array}{c}\text { Current status } \\
\text { of puppies }\end{array}$ \\
\hline S2 & 9 & DM-1 & 61 & 380 & natural & + & alive $(>1$ year $)$ \\
S3 & & DM-2 & 61 & 640 & natural & - & $\begin{array}{c}\text { dead } \\
\text { cesarean section }\end{array}$ \\
\hline
\end{tabular}

${ }^{a}$ Gestation days from the date of embryos transfer; ${ }^{b}$ death on postnatal Day 1.

Embryo transfer results. The results of embryo transfers are summarized in Table III. A total of 75 oocytes were from 7 egg donors (10.7 oocytes/egg donor) and subjected to nuclear transfer using the transgenic cells. Forty-seven embryos that had successfully fused $(72.3 \%)$ were transferred into 5 recipients and 2 surrogates (S2 and S3) delivered 3 puppies (Table IV). One (DM-1) of the puppies from S2 was healthy but the other (DM-2) died within $24 \mathrm{~h}$. This scenario was also observed in our previously reported study (22). Although DM-3 from S3 was born by Cesarean section, it was healthy with a normal body weight ( $360 \mathrm{~g})$. The two surviving puppies (DM-1 and DM-3) expressed EGFP in their claws and skin (Fig. 3A), and primary cells from these puppies were further found to express EGFP when examined under a microscope (Fig. 3B). Genetic identities of the cloned puppies with the nuclear donor fibroblasts were confirmed by microsatellite parentage analysis (Fig. 3C). Thus, two puppies were visually confirmed to be transgenic dogs by EGFP expression and further identified as cloned dogs by a microsatellite assay.

Characterization of the transgenic and cloned puppies. To confirm chromosomal insertion of the targeting vector, genomic DNA of 3 puppies (DM-1, DM-3 and control) were prepared from their umbilical cords and PCR-based genotyping was performed. DM-1 and DM-3 had the PEPCK expression cassette $(2.7 \mathrm{~kb})$ and the endogenous PEPCK gene
$(5.2 \mathrm{~kb})$ but the age-matched control had only the endogenous gene (Fig. 4A). Integration of the selection cassette was further confirmed by PCR (Fig. 4B). In addition, functional activity of the PEPCK gene in the targeting vector was estimated by real-time PCR (Fig. 4C) and immunoblotting analysis of a liver biopsy sample from DM-3 (Fig. 4D). In DM-3, PEPCK mRNA expression was 2 times higher than that of the wildtype control and PEPCK protein expression was induced. Although we confirmed that DM-3 overexpressed the PEPCK gene, this animal has not presented any symptoms associated with type 2 diabetes mellitus thus far. We continue to monitor DM-3 for the onset of diabetes-like symptoms because this type of diabetes is a late-onset disease.

\section{Discussion}

Comparing to experimental rodent models, domestic dogs offer many advantages due to their homogeneous populations, medical care availability, comparable organ sizes, cohabitation with humans and pathophysiological similarities to humans. Dogs are therefore useful for understanding the molecular basis of vascular and neural lesion pathogenesis, the actions of therapeutic agents, and the genetic and environmental influence (23). Despite the genetic and physiologic usefulness of animal model, studies of transgenic dogs have lagged behind those using laboratory rats and mice as experimental models 

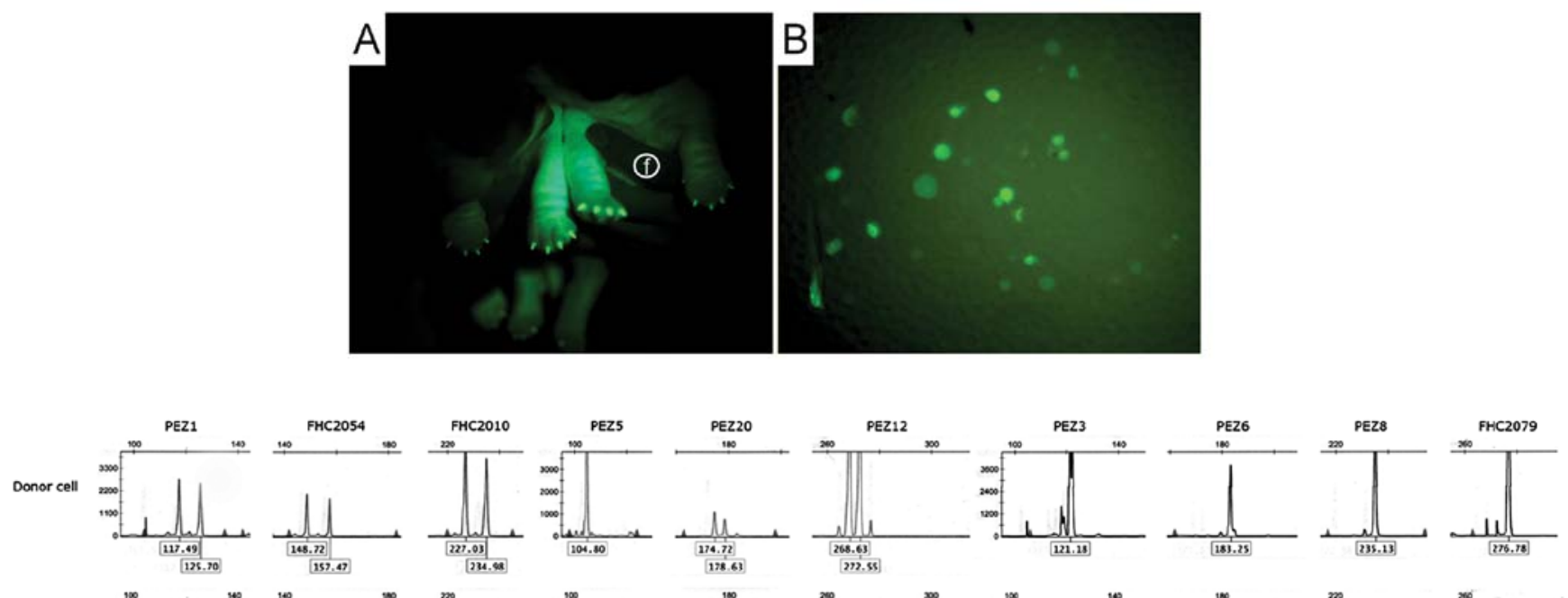

DM-2
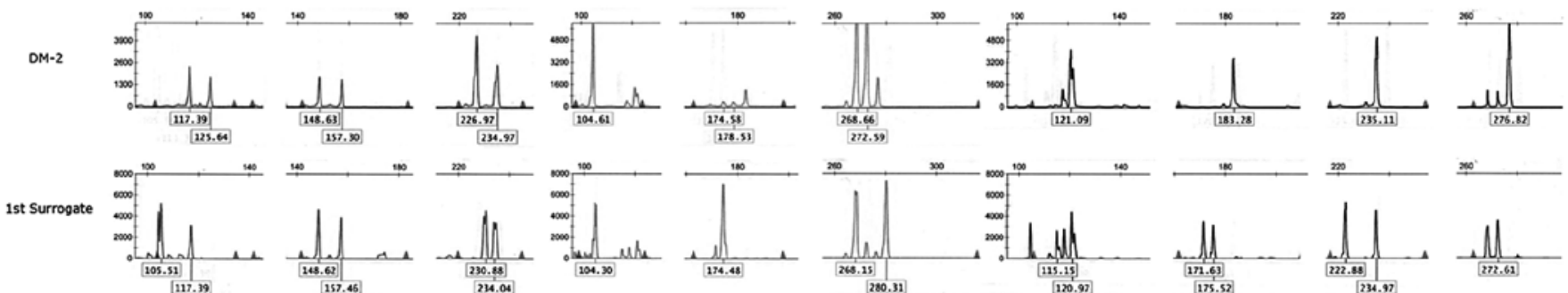

DM-4
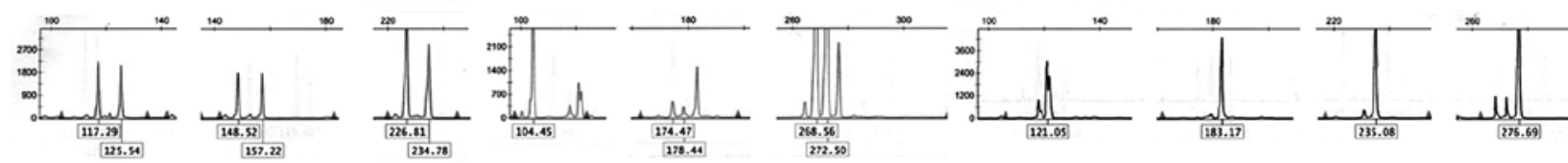

2nd Surrogate
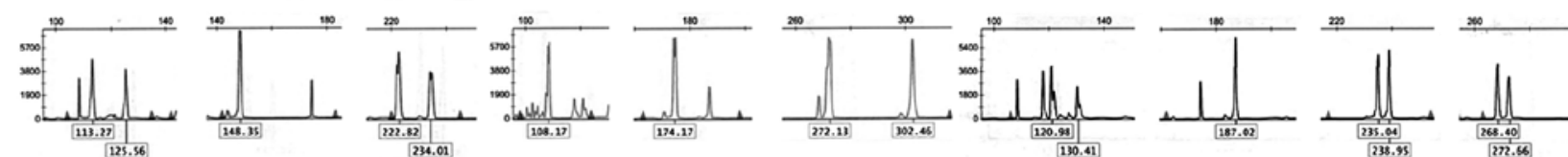

Figure 3. Identification of transgenic cloned puppies. (A) 3-month-old puppies (DM-1 and DM-3) were exposed to UV light. EGFP expression was observed in the claws and skin. f, human index figure as a negative control. (B) Primary cultured fibroblasts from DM-3 expressed EGFP observed by fluorescence microscopy (magnification, x200). (C) Microsatellite analysis of the nuclear donor cell, cloned puppies and surrogates. Genotypes at 10 polymorphic microsatellite loci were determined for genomic DNA samples isolated from the nuclear donor cell lines, cloned puppies and surrogates that delivered the puppies. Values represent the base pairs of the amplified microsatellite DNA markers for each sample.

A

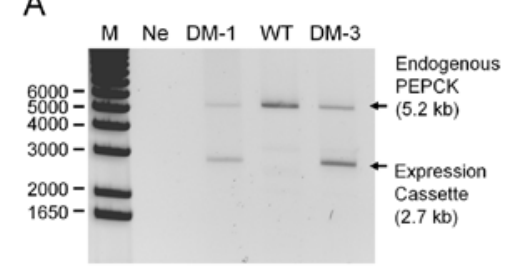

C

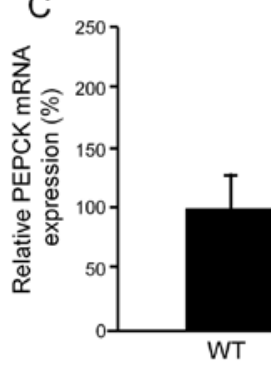

B

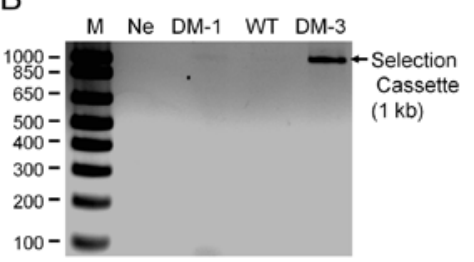

D

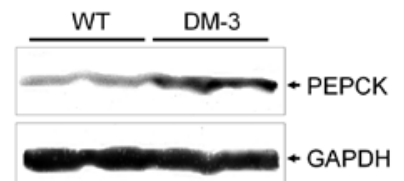

Figure 4. Confirmation of PEPCK expression in transgenic puppies. Genomic DNA was obtained from umbilical cords of DM-1, DM-3 or age-matched WT puppies. (A) Chromosomal insertion of the PEPCK expression cassette was confirmed using primers a and b described in Fig. 1C. (B) This insertion was further confirmed by nested PCR. (C) Canine PEPCK mRNA expression was measured by real-time PCR and (D) PEPCK protein expression was detected with an anti-PEPCK antibody in liver biopsy samples. Data are presented that show the percent expression of the control dog compared to that of WT. Data represent the mean \pm SEM of 3 independent experiments each performed in triplicate. ${ }^{*} \mathrm{P}<0.05$ vs. the WT dogs; M, molecular weight; Ne, PCR reaction without genomic DNA. 
of human disease. Reasons for the poor development of canine transgenic techniques include the scarcity of available canine oocytes and lack of a canine in vitro maturation system (24). In the present study, we generated two transgenic cloned puppies. One dog (DM-3) overexpressed PEPCK mRNA and protein in the liver that might cause type 2 diabetes mellitus-like symptoms. In addition, we optimized fetal fibroblasts as a nuclear source for SCNT by comparing cloning efficiencies of adult and cloned fetal fibroblasts (Table I).

Fibroblasts from various tissues have been widely used as the nuclear source for SCNT (25). Cell types of different origins exhibit various sensitivities to physical damage during the nuclear transfer procedure, affecting the overall cloning efficiencies (26). Although the cloning efficiencies of two nuclear sources for SCNT, fetal fibroblasts and adipocytes, were previously compared, no comparisons with fibroblasts have been made $(27,28)$. In this study, the cloning efficiency of fibroblasts originated from adult dog skin (2-year-old beagle) and fetal fibroblasts (25-gestation-day fetus from cloned or naturally bred animals) were validated. The cloning efficiency of the fetal fibroblast as the source for SCNT was $50.0 \%$ whereas the efficiencies of adult or cloned fetal fibroblasts were 16.6 and $10.0 \%$, respectively. Thus, the fetal fibroblasts derived from naturally bred animals were found to be the best cell source for generating transgenic dogs.

Efficient genetic engineering techniques are essential for the successful production of transgenic animals. Several studies have reported that virus-mediating gene delivery systems are useful for modifying the genetic information of target animals (29,30). Although viral systems are associated with high chromosomal integration rates, these cause unwanted side effects such as neoplastic transformation (31). On the other hand, liposome-mediated gene delivery systems are relatively safer and easier to use than the viral systems. However, these have low transfection efficiencies during long-term selection $(32,33)$. In the present study, we adopted the liposome-mediating gene delivery to generate transgenic puppies.

PEPCK is a key gluconeogenic enzyme in the liver and kidneys that has an established role in the metabolic intermediates (20). Transgenic mice overexpressing PEPCK were previously generated and show key symptoms of type 2 diabetes mellitus (21). In addition, several mice strains overexpressing the PEPCK gene were subsequently produced $(34,35)$. Based on these mouse models, we constructed a targeting vector containing canine PEPCK cDNA controlled by its promoter regions $(-746$ to $+1 \mathrm{nt}$ ) by screening the promoter activity assay (Fig. 1). This targeting vector also contained two selection marker genes, EGFP and $\mathrm{Neo}^{\mathrm{r}}$, to facilitate antibiotic screening and visual confirmation of transfection.

The genetic identity of cloned transgenic puppies produced in the current study was confirmed by microsatellite analysis and via artificial PEPCK expression using real-time PCR and immunoblotting assays (Fig. 4). Although the transgenic puppies expressed high levels of hepatic PEPCK compared to wild-type dogs, we could not detect any symptoms similar to those of type 2 diabetes mellitus. We further performed glucose tolerance tests with intravenous injections of a glucose solution $(500 \mathrm{mg} / \mathrm{kg})$ to induce diabetes-like symptoms in the transgenic dogs. Although the transgenic puppies had higher levels of serum glucose and lower levels of serum insulin than wild-type dogs, there was no significant difference between the animals. This glucose challenging might have failed due to the compensatory action of pancreatic $\beta$-cells and/or may be associated with the genetic background of the breeds. Beagles are less susceptible to diabetes mellitus than other breeds, and the onset and progression of this disease varies according to breed, gender and age (36).

In the present study, we generated cloned transgenic dogs overexpressing exogenous PEPCK in order to establish a canine model of type 2 diabetes mellitus. Additionally, we optimized fetal fibroblasts as a suitable nuclear source and a liposomemediating system for gene delivery. Although the current transgenic dogs have not presented any symptoms of type 2 diabetes mellitus, we continue to monitor the phenotypes of these animals. Further studies are needed to explore the function of the PEPCK transgene and its patterns of expression in different organs. Hepatic glucose production should also be evaluated by clamp studies. Ultimately, the current transgenic dogs may spontaneously, rapidly and predictably develop the symptoms of diabetes mellitus similar to humans such as hyperglycemia and insulin resistance. This model may be a valuable tool for improving our understanding of the pathogenesis of type 2 diabetes and for developing diagnostic and treatment strategies.

\section{Acknowledgements}

This study was supported by a grant from the Next-Generation BioGreen 21 Program (no. PJ008323), Rural Development Administration, Republic of Korea.

\section{References}

1. Wilmut I, Schnieke A, McWhir J, Kind A and Campbell K: Viable offspring derived from fetal and adult mammalian cells. Nature 385: 810-813, 1997.

2. Baguisi A, Behboodi E, Melican DT, et al: Production of goats by somatic cell nuclear transfer. Nat Biotechnol 17: 456-461, 1999.

3. Chesne P, Adenot PG, Viglietta C, Baratte M, Boulanger L and Renard JP: Cloned rabbits produced by nuclear transfer from adult somatic cells. Nat Biotechnol 20: 366-369, 2002.

4. Cibelli JB, Stice SL, Golueke PJ, et al: Cloned transgenic calves produced from nonquiescent fetal fibroblasts. Science 280: 1256 , 1998.

5. Lee BC, Kim MK, Jang G, et al: Dogs cloned from adult somatic cells. Nature 436: 641, 2005.

6. Li Z, Sun X, Chen J, et al: Cloned ferrets produced by somatic cell nuclear transfer. Dev Biol 293: 439, 2006.

7. Polejaeva IA, Chen SH, Vaught TD, et al: Cloned pigs produced by nuclear transfer from adult somatic cells. Nature 407: 86-90, 2000.

8. Wakayama T, Perry ACF, Zuccotti M, Johnson KR and Yanagimachi R: Full-term development of mice from enucleated oocytes injected with cumulus cell nuclei. Nature 394: 369-374, 1998.

9. Zhou Q, Renard JP, Le Friec G, et al: Generation of fertile cloned rats by regulating oocyte activation. Science 302: 1179, 2003.

10. Jang $\mathrm{G}$, Hong $\mathrm{S}$, Oh $\mathrm{H}$, et al: A cloned toy poodle produced from somatic cells derived from an aged female dog. Theriogenology 69: 556-563, 2008

11. Hossein MS, Jeong YW, Park SW, et al: Birth of Beagle dogs by somatic cell nuclear transfer. Anim Reprod Sci 114: 404-414, 2009.

12. Kim S, Park SW, Hossein MS, et al: Production of cloned dogs by decreasing the interval between fusion and activation during somatic cell nuclear transfer. Mol Reprod Dev 76: 483-489, 2009.

13. Hossein MS, Jeong YW, Park SW, et al: Cloning Missy: obtaining multiple offspring of a specific canine genotype by somatic cell nuclear transfer. Cloning Stem Cells 11: 123-130, 2009. 
14. Capecchi MR: Gene targeting in mice: functional analysis of the mammalian genome for the twenty-first century. Nat Rev Genet 6: 507-512, 2005.

15. Gordon JW: Transgenic animals. Int Rev Cytol 115: 171-229, 1989.

16. Palmiter RD and Brinster RL: Germ-line transformation of mice. Annu Rev Genet 20: 465-499, 1986.

17. Stacey A, Bateman J, Choi T, Mascara T, Cole W and Jaenisch R: Perinatal lethal osteogenesis imperfecta in transgenic mice bearing an engineered mutant pro-alpha 1 (I) collagen gene. Nature 332: 131, 1988.

18. Karlsson EK and Lindblad-Toh K: Leader of the pack: gene mapping in dogs and other model organisms. Nat Rev Genet 9 : 713-725, 2008

19. Ostrander EA, Galibert F and Patterson DF: Canine genetics comes of age. Trends Genet 16: 117-124, 2000.

20. Hanson RW and Reshef L: Regulation of phosphoenolpyruvate carboxykinase (GTP) gene expression. Annu Rev Biochem 66 581-611, 1997.

21. Valera A, Pujol A, Pelegrin M and Bosch F: Transgenic mice overexpressing phosphoenolpyruvate carboxykinase develop non-insulin-dependent diabetes mellitus. Proc Natl Acad Sci USA 91: 9151, 1994.

22. Hong IH, Jeong YW, Shin T, et al: Morphological abnormalities, impaired fetal development and decrease in myostatin expression following somatic cell nuclear transfer in dogs. Mol Reprod Dey 5: 337-346, 2011.

23. Tsai KL, Clark LA and Murphy KE: Understanding hereditary diseases using the dog and human as companion model systems. Mamm Genome 18: 444-451, 2007.

24. Luvoni GC, Chigioni S, Allievi E and Macis D: Factors involved in vivo and in vitro maturation of canine oocytes. Theriogenology 63: 41-59, 2005

25. Powell A, Talbot N, Wells K, Kerr D, Pursel V and Wall R: Cell donor influences success of producing cattle by somatic cell nuclear transfer. Biol Reprod 71: 210, 2004.
26. Wells DN, Misica PM and Tervit HR: Production of cloned calves following nuclear transfer with cultured adult mural granulosa cells. Biol Reprod 60: 996, 1999.

27. Hong SG, Jang G, Kim MK, et al: Dogs cloned from fetal fibroblasts by nuclear transfer. Anim Reprod Sci 115: 334-339, 2009.

28. Oh HJ, Park JE, Kim MJ, et al: Recloned dogs derived from adipose stem cells of a transgenic cloned beagle. Theriogenology 75: 1221-1231, 2011

29. Bosch P, Pratt SL and Stice SL: Isolation, characterization, gene modification, and nuclear reprogramming of porcine mesenchymal stem cells. Biol Reprod 74: 46, 2006.

30. Gómez MC, Pope CE, Kutner RH, et al: Generation of domestic transgenic cloned kittens using lentivirus vectors. Cloning Stem Cells 11: 167-176, 2009.

31. Sokol DL and Gewirtz AM: Gene therapy: basic concepts and recent advances. Crit Rev Eukaryot Gene Expr 6: 29, 1996.

32. Chen QR, Zhang L, Luther PW and Mixson AJ: Optimal transfection with the HK polymer depends on its degree of branching and the $\mathrm{pH}$ of endocytic vesicles. Nucleic Acids Res 30: 1338, 2002.

33. Nikcevic G, Kovacevic-Grujicic N and Stevanovic M: Improved transfection efficiency of cultured human cells. Cell Biol Int 27: 735-737, 2003.

34. Sun Y, Liu S, Ferguson S, et al: Phosphoenolpyruvate carboxykinase overexpression selectively attenuates insulin signaling and hepatic insulin sensitivity in transgenic mice. J Biol Chem 277: 23301, 2002.

35. Hanson RW and Hakimi P: Born to run; the story of the PEPCKCmus mouse. Biochimie 90: 838-842, 2008.

36. Fall T, Hamlin HH, Hedhammar A, Kämpe O and Egenvall A: Diabetes mellitus in a population of 180,000 insured dogs: incidence, survival, and breed distribution. J Vet Intern Med 21: 1209-1216, 2007. 